\title{
Podridão peduncular em manga: patogenicidade, agressividade e caracterização de isolados pela análise isoenzimática
}

\author{
Severina Rodrigues de Oliveira Lins ${ }^{1}$, Adriana Pereira de Melo ${ }^{1}$, Sônia Maria Alves de Oliveira ${ }^{1}$
}

${ }^{1}$ Universidade Federal Rural de Pernambuco, Departamento de Agronomia, Área de Fitossanidade, Av. Dom Manual de Medeiros, s/n, Dois Irmãos, CEP:52171-900, Recife-PE. Brasil. Fone: (81) 3320-6216.

Autor para correspondência: Severina Rodrigues de Oliveira Lins (linsnina@ hotmail.com)

Data de chegada: 10/04/2010. Aceito para publicação em: 10/04/2013.

\section{RESUMO}

Lins, S.R.O.; Melo, A.P.; Oliveira, S.M.A. Podridão peduncular em manga: patogenicidade, agressividade e caracterização de isolados pela análise isoenzimática. Summa Phytopathologica, v.39, n.4, p.263-270, 2013.

Trinta e quatro isolados de Lasiodiplodia theobromae coletados de diferentes órgãos de mangueira, em duas épocas sazonais diferentes, em distintas regiões geográficas, foram avaliados quanto à patogenicidade, agressividade e produção de enzimas em substratos sólidos específicos e em sistemas de géis de poliacrilamida. Independente do órgão do qual foram isolados, todos foram patogênicos quando inoculados em manga, diferindo no grau de agressividade, sendo separados em três grupos: altamente, medianamente e fracamente agressivos. As atividades amilolítica, celulolítica, lipolítica e proteolítica foram estimadas por meio da difusão enzimática em meio sólido específico e mensuração do halo de degradação do substrato. As atividades das enzimas á-esterase, â-esterase, leucina-aminopeptidase, fosfatase ácida e proteínas totais foram analisadas em géis de poliacrilamida com meios de revelação específicos para cada análise. Os padrões eletroforéticos bem como as análises das enzimas extracelulares apresentaram polimorfismo, demonstrando a diversidade na base genética dos isolados, independente da época de coleta, região geográfica e órgão de isolamento.

Palavras-chave adicionais: Lasiodiplodia theobromae, Mangifera indica, polimorfismo, géis de poliacrilamida

\section{ABSTRACT}

Lins, S.R.O.; Melo, A.P.; Oliveira, S.M.A. Mango stem rot: pathogenicity, aggressiveness and characterization of isolates based on isoenzymatic analysis. Summa Phytopathologica, v.39, n.4, p.263-270, 2013.

Thirty-four Lasiodiplodia theobromae isolates collected from different organs of mango trees, in two different seasonal periods, at different geographical regions, were evaluated for pathogenicity, aggressiveness and production of enzymes on specific solid substrates and in polyacrylamide gel systems. Regardless of the organ from which they were collected, all isolates were pathogenic when inoculated into mango, differing in the aggressiveness degree, based on which they were separated into three groups: high, medium and low aggressiveness. The amylolytic, cellulolytic, lipolytic and proteolytic activities were estimated by means of enzyme diffusion on specific solid medium and measurement of the substrate degradation halo. The activities of enzymes á-esterase, â-esterase, leucineaminopeptidase, acid phosphatase and total protein were analyzed on polyacrylamide gels with specific revelation media for each analysis. The electrophoretic patterns and the analysis of extracellular enzymes showed polymorphism, evidencing the diversity in the genetic basis of isolates, regardless of collection period, geographic region and organ from which the isolates were collected.

Additional keywords: Lasiodiplodia theobromae, Mangifera indica, polymorphism, polyacrylamide gels

Lasiodiplodia theobromae (Pat.) Riffon \& Maubl. (Botryosphaeria Ces \& De Not.) é comumente encontrado em mais de 500 espécies de árvores, incluindo angiospermas e gimnospermas, em todo mundo, tanto como endofítico quanto como patógeno oportunista (4). Apresenta grande variabilidade nas características morfológica e fisiológica $(5,21)$, e pouca especialização patogênica, estando associado a processos patogênicos em plantas, geralmente, estressadas e/ou submetidas a ferimentos naturais provocados por insetos ou outros agentes, bem como pelo próprio homem, através das práticas culturais (17).

Na mangueira, causa doenças conhecidas como morte descendente, seca de ponteiros, podridão basal ou podridão peduncular da fruta. Pode infectar tanto na fase de produção em mudas, caule, ramos, folhas e flores, como na fase de pós-colheita, provocando o apodrecimento de frutas armazenadas (23).

Nas frutas, o fungo penetra pelo pedúnculo ou ferimentos formando lesões escuras na base, com bordas definidas. Posteriormente, os tecidos lesados podem rachar, expondo a polpa da fruta. Por outro lado, o fungo pode permanecer quiescente nos tecidos da fruta e, após a colheita, ser ativado durante o período climatério, quando essa libera exsudatos que favorecem seu desenvolvimento, e causa o apodrecimento da mesma pela destruição dos tecidos (12), 
devido à ação de enzimas e toxinas, que favorecem a penetração, a colonização, a obtenção de nutrientes e/ou contribuem para interferir nas reações de defesa da fruta.

Tem-se observado aumento acentuado da incidência deste fitopatógeno nas regiões produtoras de mangas em todo Nordeste, ocasionando danos expressivos tanto na fase de produção quanto na pós-colheita (13). Este fato é favorecido pelos métodos utilizados para a indução floral, como as aplicações constantes de nitrato de potássio ou paclobutrazol, aliados à exposição prolongada das plantas ao estresse hídrico (26).

Estudos sobre este patossistema ainda são escassos. Com isso, fazem-se necessárias mais pesquisas que auxiliem no melhor entendimento do comportamento desse fitopatógeno em mangas na fase de pós-colheita, dando ênfase a conhecimentos de patogenicidade, agressividade e produção de enzimas, pois de modo geral, os microrganismos apresentam uma grande variabilidade que pode refletir em sua morfologia, fisiologia ou patogenicidade. Variações fisiológicas dentro de uma população podem resultar em variações na patogenicidade dos isolados. Os estudos desses parâmetros norteiam na busca de estratégias de controle para um fitopatógeno. Dessa forma, o objetivo para o desenvolvimento desta pesquisa foi avaliar o comportamento de diferentes isolados de L. theobromae de mangueiras, quanto à patogenicidade, agressividade e produção de enzimas inter e extracelulares.

\section{MATERIAL E MÉTODOS}

Os isolados foram obtidos de folhas e ramos de mangueiras com sintomas de seca de ponteiro e de frutas com podridão peduncular, em pomares situados em Petrolina - PE e Juazeiro - BA, nos anos de 2009 e 2010. A primeira coleta (C1) foi realizada no período "chuvoso" (outubro de 2009) e a segunda (C2), no período "seco" (março de 2010). Foram obtidos vinte isolados na $\mathrm{C} 1$ e quatorze isolados na $\mathrm{C} 2$. O material vegetal de cada coleta foi acondicionado em sacos de papel, os quais foram etiquetados e mantidos em caixa de isopor, contendo gelo, para transporte até o Laboratório de Patologia Pós-colheita da Universidade Federal Rural de Pernambuco, onde foram realizados os experimentos.

Para o isolamento, seguiu-se a metodologia de Menezes \& Assis (16). Os fragmentos foram depositados em placas de Petri contendo meio batata-dextrose-ágar (BDA) e incubados em condições de laboratório, a temperatura de $25 \pm 2{ }^{\circ} \mathrm{C}$ até o crescimento do fungo. Com base na literatura especializada, realizou-se a identificação da espécie $L$. theobromae pelas estruturas características formadas pelo fungo (4). Os isolados foram transferidos para tubos de ensaio contendo BDA, bem como, preservados pelo método Castellani.

Para a avaliação da patogenicidade e agressividade dos isolados, mangas sadias, cv. Tommy Atkins, em estádio dois de maturação comercial, foram lavadas com água corrente e sabão e secas sobre papel toalha em temperatura ambiente. O inóculo constituiu-se de suspensão de $10^{6}$ conídios/mL de L. theobromae, cultivados em placas de Petri com BDA durante 25 dias. Após este tempo, foram retirados picnídios das colônias e macerados em $2 \mathrm{~mL}$ de água destilada utilizandose para isto, pistilo e cadinho. Posteriormente, o macerado foi filtrado em gaze, e realizada a contagem dos esporos em câmara de Neubauer e ajustada a concentração para $10^{6}$ conídios $/ \mathrm{mL}$. As frutas foram inoculadas, na região equatorial, fazendo-se ferimentos com auxílio de um vazador com cinco pontas de $2 \mathrm{~mm}$ de profundidade. Utilizou-se, para a inoculação, uma micropipeta com capacidade para $10 \mu \mathrm{L}$ da suspensão de conídios, os quais foram depositados em cada ferimento. Após a inoculação, foi promovida, por 48 horas, uma câmara úmida mantendo-se temperatura e umidade relativa controladas de $28^{\circ} \mathrm{C} \pm 2$ e $84 \%$, respectivamente. A testemunha foi inoculada com $10 \mu \mathrm{L}$ de água destilada esterilizada sobre o ferimento. As avaliações foram realizadas diariamente a partir da retirada da câmara úmida, até o quinto dia, medindo-se o diâmetro da lesão (DL), expresso em mm, com paquímetro. Foi realizado o reisolamento e a comparação dos isolados recuperados com aqueles utilizados como inóculo inicial. O desenho experimental foi inteiramente casualizado, com seis frutas para cada isolado, que se constituíram as repetições. Os dados foram submetidos à análise de variância e teste de Scott-Knott a 5\% de probabilidade para comparação das médias.

Para a caracterização dos isolados pela produção de enzimas hidrolíticas, uma alíquota de $200 \mu \mathrm{L}$ de suspensão de conídios com $10^{4}$ conídios/mL foi depositada sobre o meio Agar-água, em placa de Petri, e distribuída sobre a superfície do meio com auxílio de uma alça de Drigalski. Após 12 horas estas placas foram observadas ao microscópio óptico e apenas um conídio germinado foi retirado da placa e transferido para outra placa contendo meio de cultura BDA, obtendo-se a cultura monospórica. Discos de cultura $(6 \mathrm{~mm}$ de diâmetro) de cada um dos 34 isolados de L. theobromae, com cinco dias de crescimento em BDA, foram retirados da borda das colônias e transferidos, individualmente, para o centro de placas de Petri, contendo um dos meios específicos às atividades amilolítica, celulolítica, lipolítica e proteolítica. Os procedimentos adotados para testar a habilidade dos isolados em degradar amido e lipídio em meio ácido, celulose e proteína foram realizados conforme metodologia descrita por Menezes \& Assis (16). Em cada ensaio, utilizou-se o delineamento experimental inteiramente casualizado, com seis repetições, por tratamento. Os halos de degradação dos substratos, pela atividade enzimática, expressos em mm, foram medidos com auxílio de régua milimetrada. Foi realizada a análise de variância dos dados, e as médias agrupadas pelo teste de Scott-Knott $(\mathrm{P}=0,05)$, bem como a correlação destes dados com os de agressividade, pelo coeficiente de Pearson a 5\% de probabilidade.

Para averiguar o perfil eletroforético de isoenzimas e proteínas produzidas pelos isolados foi preparado o extrato protéico da massa micelial, transferindo-se dois discos de meio de cultura BDA, contendo estruturas dos isolados de L. theobromae, obtidos de cultura monospórica, crescidos por 48 horas, para meio líquido BD (batatadextrose), os quais permaneceram em alternância luminosa de 12 horas, a $27^{\circ} \mathrm{C}$, por 48 horas. Após este período de incubação, coletou-se a massa micelial por filtração em papel filtro, a qual foi lavada extensivamente com água destilada/esterilizada, gelada, e deixada secar em temperatura controlada a $15^{\circ} \mathrm{C}$, por 30 minutos. Pesou-se $1,0 \mathrm{~g}$ do micélio e macerou-se com nitrogênio líquido em almofariz com pistilo, mantido em banho de gelo, sendo adicionados $1 \mathrm{~mL}$ de tampão Trisglicina a $0,125 \mathrm{M}, \mathrm{pH} \mathrm{8,2;300} \mathrm{mg} \mathrm{de} \mathrm{polinilpirrolidona} \mathrm{(PVP)} \mathrm{e} 300$ $\mathrm{mg}$ de sacarose. $\mathrm{O}$ macerado foi transferido para microtubos com capacidade para 1,5 mL. Realizou-se centrifugação do extrato fúngico a $14.000 \mathrm{rpm}$ por 30 minutos, em centrífuga refrigerada. Os sobrenadantes, constituindo os extratos protéicos, foram coletados com micropipeta, transferidos para novos eppendorffs e congelados a $4^{\circ} \mathrm{C}$, para utilização posterior. $\mathrm{O}$ preparo dos géis, a migração eletroforética e as colorações para revelar as atividades enzimáticas de proteínas totais, a-esterase, $B$-esterase e fosfatase ácida foram realizadas de acordo com a metodologia descrita por Alfenas et al. (1). Na atividade da leucina aminopeptidase, seguiu-se a metodologia descrita por Couto et al. (6). 
Para a interpretação dos zimogramas, foram levados em conta a intensidade, coloração, número e posição das bandas no gel de poliacrilamida. No cálculo da mobilidade relativa (RF) das bandas usou-se a fórmula: $\mathrm{RF}=(\mathrm{d} / \mathrm{D}) \mathrm{x} 100$, em que: $\mathrm{d}=$ distância percorrida pela molécula; $\mathrm{D}=$ distância percorrida pelo corante marcador (1). O coeficiente de similaridade (CS), (Apêndices), entre os isolados foi calculado com os valores da mobilidade relativa das bandas formadas nos géis, utilizando-se a fórmula descrita por Hansen et al. (8), onde são consideradas, para cada par de isolados, as bandas em comum, dividido pelo número total de bandas do mesmo par de isolados, conforme a fórmula: $\mathrm{Cs}=2\left(\mathrm{bc} / \mathrm{b}_{1}+\mathrm{b}_{2}\right)$ x 100 , em que: $\mathrm{bc}=$ número de bandas comuns a dois isolados; $b_{1}+b_{2}=$ número total de bandas formadas pelo par de isolado.

\section{RESULTADOS E DISCUSSÃO}

Todos os isolados, independente de qual órgão da planta foi retirado, mostraram-se patogênicos quando inoculados em frutas e os sintomas característicos daqueles, inicialmente descritos para a fruta, surgiram 48 horas após a inoculação, inclusive com intensa esporulação sobre os tecidos infectados. A partir desses tecidos, foram reisolados os isolados, confirmando-se, assim, os princípios dos Postulados de
Koch. No centro das lesões, verificou-se exsudação de albume líquido provavelmente provocado pela ação necrotrófica do fitopatógeno que desagrega os tecidos na região afetada e estes não mais suportam a elevada pressão interna.

Atendendo aos princípios da patogenicidade e agressividade, descritos por Blum et al. (3), o isolado mais agressivo foi selecionado pelas leituras dos diâmetros das lesões do quinto dia após a inoculação. Assim, de acordo com o teste de agrupamento Scott-Knott, os 34 isolados de $L$. theobromae inoculados nas frutas mostraram agressividade variada, suficientes para separá-los em três grupos de agressividade: alta (LTR2, LTR19, LTR20, LTM221, LTR224), intermediária (LTR231, LTR13, LTR17, LTR27, LTR10, LTR11, LTR24, LTR212, LTR9, LTR23, LTR18, LTM207, LTM7, LTR25, LTR21), e baixa (LTR225, LTF31, LTR216, LTR203, LTR206, LTR228, LTF28, LTR12, LTM222, LTM220, LTF1, LTR204, LTR232, LTR5) (Tabela 1). O gênero Lasiodiplodia é notoriamente variável em relação a determinadas características (4) e a agressividade é uma delas, demonstrada com diversas espécies. Essa variação em relação ao comportamento de isolados de $L$. theobromae já foi constatada anteriormente em outros estudos $(5,11,21)$, mostrando a variabilidade genética dentro da espécie. Quanto à origem, foram encontrados isolados provenientes de cada uma das regiões amostradas, nos três grupos de agressividade (Tabela 1).

Tabela 1. Agressividade de isolados de Lasiodiplodia theobromae, obtidos de mangueira, expressa pelo diâmetro de lesão, relacionados segundo suas regiões de origem, cultivar da mangueira, parte da planta e época de coleta ( $1=$ outubro de 2009; $2=$ março de 2010)

\begin{tabular}{|c|c|c|c|c|c|}
\hline Isolado & Diâmetro da Lesão*(mm) & Cidade de Origem & Cultivar de mangueira & Local de Origem & Época de Coleta \\
\hline LTR2 & $73,20 \mathrm{a}$ & Petrolina-PE & Tommy Atkins & Ramo & 1 \\
\hline LTR 19 & $72,00 \mathrm{a}$ & Petrolina- PE & Tommy Atkins & Ramo & 1 \\
\hline LTR20 & $68,30 \mathrm{a}$ & Petrolina- PE & Tommy Atkins & Ramo & 1 \\
\hline LTM221 & $62,20 \mathrm{a}$ & Juazeiro-BA & Keit & Fruta & 2 \\
\hline LTR 224 & $62,10 \mathrm{a}$ & Juazeiro-BA & Tommy Atkins & Ramo & 2 \\
\hline LTR231 & $53,20 \mathrm{~b}$ & Petrolina- PE & Tommy Atkins & Ramo & 2 \\
\hline LTR 13 & $51,50 \mathrm{~b}$ & Petrolina- PE & Haden & Ramo & 1 \\
\hline LTR 17 & $50,20 \mathrm{~b}$ & Petrolina- PE & Tommy Atkins & Ramo & 1 \\
\hline LTR27 & $49,62 \mathrm{~b}$ & Juazeiro-BA & Tommy Atkins & Ramo & 1 \\
\hline LTR 10 & $48,20 \mathrm{~b}$ & Petrolina-PE & Tommy Atkins & Ramo & 1 \\
\hline LTR 11 & $47,40 \mathrm{~b}$ & Petrolina-PE & Tommy Atkins & Ramo & 1 \\
\hline LTR24 & $45,30 \mathrm{~b}$ & Juazeiro-BA & Tommy Atkins & Ramo & 1 \\
\hline LTR 212 & $45,00 \mathrm{~b}$ & Petrolina-PE & Tommy Atkins & Ramo & 2 \\
\hline LTR9 & $44,20 \mathrm{~b}$ & Petrolina-PE & Keit & Ramo & 1 \\
\hline LTR 23 & $43,80 \mathrm{~b}$ & Petrolina-PE & Palmer & Ramo & 1 \\
\hline LTR 18 & $41,60 \mathrm{~b}$ & Juazeiro-BA & Tommy Atkins & Ramo & 1 \\
\hline LTM207 & $36,50 \mathrm{~b}$ & Juazeiro-BA & Hadem & Fruta & 2 \\
\hline LTM7 & $36,20 \mathrm{~b}$ & Juazeiro-BA & Tommy Atkins & Fruta & 1 \\
\hline LTR 25 & $35,70 \mathrm{~b}$ & Petrolina-PE & Tommy Atkins & Ramo & 1 \\
\hline LTR21 & $34,40 \mathrm{~b}$ & Juazeiro-BA & Haden & Ramo & 1 \\
\hline LTR 225 & $33,10 \mathrm{c}$ & Petrolina-PE & Tommy Atkins & Ramo & 2 \\
\hline LTF31 & $28,90 \mathrm{c}$ & Juazeiro-Ba & Tommy Atkins & Folha & 1 \\
\hline LTR 216 & $28,40 \mathrm{c}$ & Petrolina-PE & Keit & Ramo & 2 \\
\hline LTR 203 & $19,60 \mathrm{c}$ & Petrolina-PE & Tommy Atkins & Ramo & 2 \\
\hline LTR 206 & $17,60 \mathrm{c}$ & Juazeiro-BA & Tommy Atkins & Ramo & 2 \\
\hline LTR 228 & $17,30 \mathrm{c}$ & Petrolina-PE & Palmer & Ramo & 2 \\
\hline LTF28 & $16,20 \mathrm{c}$ & Petrolina-PE & Tommy Atkins & Folha & 1 \\
\hline LTR 12 & $15,90 \mathrm{c}$ & Juazeiro-BA & Hadem & Ramo & 1 \\
\hline LTM 222 & $14,60 \mathrm{c}$ & Juazeiro-BA & Tommy Atkins & Fruta & 2 \\
\hline LTM220 & $12,90 \mathrm{c}$ & Petrolina-PE & Tommy Atkins & Fruta & 2 \\
\hline LTF1 & $12,40 \mathrm{c}$ & Petrolina-PE & Tommy Atkins & Folha & 1 \\
\hline LTR 204 & $00,88 \mathrm{c}$ & Petrolina-PE & Kent & Ramo & 2 \\
\hline LTR 232 & $00,81 \mathrm{c}$ & Petrolina-PE & Kent & Ramo & 2 \\
\hline LTR5 & $00,67 \mathrm{c}$ & Juazeiro-BA & Tommy Atkins & Folha & 1 \\
\hline $\mathrm{CV}(\%)$ & 30,352 & & & & \\
\hline
\end{tabular}

*Média de seis repetições; Médias seguidas da mesma letra não diferem pelo teste de Scott-Knott $(\mathrm{P}=0,05)$. 
Entretanto, em relação ao órgão do qual foi feito o isolamento, constatou-se que os isolados de folha exibiram baixa agressividade. Em contra partida, é notório a inespecificidade desse patógeno em causar lesões em diferentes tecidos da planta, mesmo em outros hospedeiros que não àqueles de onde foram isolados (21), corroborando com as conclusões firmadas por Varma \& Bilgrami (24), que consideram que do ponto de vista ecológico, o fungo $L$. theobromae é considerado um parasita não especializado, podendo ser amplamente distribuído em mais de 500 espécies vegetais e um mesmo isolado é capaz de infectar diferentes hospedeiros.

Quanto à caracterização dos isolados pela produção de enzimas hidrolíticas, observou-se que os isolados de L. theobromae apresentaram atividade hidrolítica extracelular para degradação dos substratos, após 48 horas, e foram separados em grupos em função do diâmetro dos halos produzidos: amido, degradação caracterizada por halo translúcido com coloração amarelada, geraram três grupos; celulose, com exceção dos isolados LTF1, LTR204, LTR206 e LTR228, degradação identificada pelo halo opaco e estreito, resultaram em quatro grupos; proteína, degradação observada como halo translúcido, produziram cinco grupos; e lipídio, exceto o isolado LTR13, degradação expressa como halo na forma de precipitado, resultaram em quatro grupos (Tabela 2). Os isolados LTR2 e LTR21 exibiram similar padrão enzimático, embora não tenham demonstrado padrão semelhante de agressividade. Os isolados que não apresentaram atividade celulolítica mostraram uma fraca agressividade. O mesmo evento verificou-se para o isolado LTR13, na produção de lipídeos, sugerindo que estas enzimas são importantes para o bom desempenho nutricional desses isolados.

Assim como no teste de agressividade, não houve influência da época de coleta, local da planta e região de origem dos isolados quanto à produção ou não das enzimas estudadas com exceção dos isolados LTR13 e LTR17 para a produção de lipídios. Entretanto, esses isolados foram hábeis na produção de amido, com destaque para o isolado LTR17, e proteínas. Comportamentos semelhantes exibiram os isolados LTR5, LTR18 e LTR206 com fraca produção de proteínas. Em contrapartida, o isolado LTR5 agrupou-se entre aqueles com produção fraca de celulose; LTR18, com uma produção intermediária de celulose e amido, e LTR206, com uma produção significante de amido em relação aos demais isolados.

O fungo atua na busca por nutrientes, degradando várias substâncias como a celulose, as lipoproteínas e o amido, para atender aos requerimentos exigidos às suas atividades fisiológicas. $\mathrm{Na}$ fase de

Tabela 2. Atividade enzimática $(\mathrm{mm})$ de isolados de Lasiodiplodia theobromae por difusão em substratos sólidos específicos.

\begin{tabular}{|c|c|c|c|c|c|c|c|}
\hline \multicolumn{8}{|c|}{ Atividade } \\
\hline \multicolumn{2}{|c|}{ Amilolítica } & \multicolumn{2}{|c|}{ Celulolítica } & \multicolumn{2}{|c|}{ Lipolítica } & \multicolumn{2}{|c|}{ Proteolítica } \\
\hline Isolado & $\operatorname{Halo}^{1}(\mathrm{~mm})$ & Isolado & $\mathrm{Halo}^{1}(\mathrm{~mm})$ & Isolado & $\operatorname{Halo}^{1}(\mathrm{~mm})$ & Isolado & $\operatorname{Halo}^{1}(\mathrm{~mm})$ \\
\hline LTR25 & 38,0 a & LTM207 & $32,0 \mathrm{a}$ & LTR9 & 39,0 a & LTR27 & 30,0 a \\
\hline LTR2 & $28,0 \mathrm{a}$ & LTR23 & 28,0 a & LTR23 & $33,0 \mathrm{a}$ & LTR24 & 28,8 a \\
\hline LTR 221 & $28,0 \mathrm{a}$ & LTM7 & $16,0 \mathrm{~b}$ & LTR 203 & $31,0 \mathrm{a}$ & LTR 11 & $28,5 \mathrm{a}$ \\
\hline LTR 212 & $26,0 \mathrm{a}$ & LTR 19 & $14,0 \mathrm{~b}$ & LTR 2 & $31,0 \mathrm{a}$ & LTR231 & $27,7 \mathrm{a}$ \\
\hline LTR 21 & $26,0 \mathrm{a}$ & LTR25 & $14,0 \mathrm{~b}$ & LTR 232 & $31,0 \mathrm{a}$ & LTR 25 & $27,6 \mathrm{a}$ \\
\hline LTR206 & $26,0 \mathrm{a}$ & LTR5 & $12,0 \mathrm{~b}$ & LTR 21 & $27,0 \mathrm{a}$ & LTR 21 & $27,4 \mathrm{a}$ \\
\hline LTR 17 & $25,0 \mathrm{a}$ & LTR27 & $11,0 \mathrm{~b}$ & LTM222 & $26,0 \mathrm{a}$ & LTR2 16 & 27,3 a \\
\hline LTF 28 & $23,0 \mathrm{~b}$ & LTM221 & $11,0 \mathrm{~b}$ & LTR231 & $24,0 \mathrm{~b}$ & LTR 2 & $27,2 \mathrm{a}$ \\
\hline LTR20 & $23,0 \mathrm{~b}$ & LTR 18 & $10,0 \mathrm{~b}$ & LTR 206 & $24,0 \mathrm{~b}$ & LTR 23 & $26,8 \mathrm{a}$ \\
\hline LTR23 & $23,0 \mathrm{~b}$ & LTR20 & $10,0 \mathrm{~b}$ & LTR 12 & $22,0 \mathrm{~b}$ & LTR 228 & 25,9 a \\
\hline LTR 18 & $22,0 \mathrm{~b}$ & LTF31 & $10,0 \mathrm{~b}$ & LTR 25 & $21,0 \mathrm{~b}$ & LTR20 & $25,8 \mathrm{a}$ \\
\hline LTR 216 & $22,0 \mathrm{~b}$ & LTR216 & $10,0 \mathrm{~b}$ & LTF 1 & $21,0 \mathrm{~b}$ & LTR 212 & $25,2 \mathrm{~b}$ \\
\hline LTR 11 & $22,0 \mathrm{~b}$ & LTM222 & $10,0 \mathrm{~b}$ & LTR 224 & $20,0 \mathrm{~b}$ & LTM220 & $24,7 \mathrm{~b}$ \\
\hline LTF1 & $22,0 \mathrm{~b}$ & LTR13 & $09,0 \mathrm{~b}$ & LTR 225 & $20,0 \mathrm{~b}$ & LTR19 & $24,6 \mathrm{~b}$ \\
\hline LTR204 & $21,0 \mathrm{~b}$ & LTR 10 & $08,0 \mathrm{~b}$ & LTR 212 & $19,0 \mathrm{~b}$ & LTM207 & $24,5 \mathrm{~b}$ \\
\hline LTR31 & $20,0 \mathrm{~b}$ & LTR231 & $08,0 \mathrm{~b}$ & LTR 19 & $19,0 \mathrm{~b}$ & LTM221 & $24,5 \mathrm{~b}$ \\
\hline LTM207 & $20,0 \mathrm{~b}$ & LTR 11 & $08,0 \mathrm{~b}$ & LTF3 1 & $19,0 \mathrm{~b}$ & LTF28 & $24,3 \mathrm{~b}$ \\
\hline LTR 12 & $20,0 \mathrm{~b}$ & LTR24 & $08,0 \mathrm{~b}$ & LTR 10 & $18,0 \mathrm{c}$ & LTR 17 & $24,2 \mathrm{~b}$ \\
\hline LTR 13 & $19,0 \mathrm{~b}$ & LTR225 & $07,0 \mathrm{~b}$ & LTR 228 & $17,0 \mathrm{c}$ & LTR 13 & $23,7 \mathrm{~b}$ \\
\hline LTR27 & $19,0 \mathrm{~b}$ & LTR9 & $08,0 \mathrm{~b}$ & LTM207 & $15,0 \mathrm{c}$ & LTF3 1 & $23,5 \mathrm{~b}$ \\
\hline LTR 203 & $18,0 \mathrm{c}$ & LTR 2 & $06,0 \mathrm{c}$ & LTM7 & $14,0 \mathrm{c}$ & LTM 222 & $22,8 \mathrm{~b}$ \\
\hline LTR24 & $17,0 \mathrm{c}$ & LTF28 & $06,0 \mathrm{c}$ & LTM221 & $14,0 \mathrm{c}$ & LTR203 & $22,6 \mathrm{~b}$ \\
\hline LTM222 & $17,0 \mathrm{c}$ & LTM21 & $06,0 \mathrm{c}$ & LTR 11 & $13,0 \mathrm{c}$ & LTF1 & $21,6 \mathrm{~b}$ \\
\hline LTR 228 & $16,0 \mathrm{c}$ & LTR 203 & $04,0 \mathrm{c}$ & LTR 18 & $13,0 \mathrm{c}$ & LTM7 & $21,6 \mathrm{~b}$ \\
\hline LTR 19 & $16,0 \mathrm{c}$ & LTR 17 & $04,0 \mathrm{c}$ & LTF28 & $12,0 \mathrm{c}$ & LTR 225 & $19,4 \mathrm{c}$ \\
\hline LTR224 & $16,0 \mathrm{c}$ & LTM 220 & $04,0 \mathrm{c}$ & LTR 216 & $12,0 \mathrm{c}$ & LTR 224 & $19,3 \mathrm{c}$ \\
\hline LTR231 & $16,0 \mathrm{c}$ & LTR 232 & $04,0 \mathrm{c}$ & LTR5 & $12,0 \mathrm{c}$ & LTR9 & $17,6 \mathrm{c}$ \\
\hline LTR 225 & $14,0 \mathrm{c}$ & LTR 212 & $03,0 \mathrm{c}$ & LTR20 & $11,0 \mathrm{c}$ & LTR 12 & $17,2 \mathrm{c}$ \\
\hline LTM220 & $13,0 \mathrm{c}$ & LTR 12 & $02,0 \mathrm{~d}$ & LTM 220 & $11,0 \mathrm{c}$ & LTR10 & $16,8 \mathrm{c}$ \\
\hline LTM7 & $12,0 \mathrm{c}$ & LTR 224 & $02,0 \mathrm{~d}$ & LTR24 & $11,0 \mathrm{c}$ & LTR 232 & $16,7 \mathrm{c}$ \\
\hline LTR5 & $10,0 \mathrm{c}$ & LTF1 & $0,0 \mathrm{~d}$ & LTR 204 & $10,0 \mathrm{c}$ & LTR204 & $14,2 \mathrm{c}$ \\
\hline LTR 9 & $10,0 \mathrm{c}$ & LTR204 & $0,0 \mathrm{~d}$ & LTR27 & $09,0 \mathrm{c}$ & LTR206 & $11,9 \mathrm{~d}$ \\
\hline LTR 10 & $10,0 \mathrm{c}$ & LTR206 & $0,0 \mathrm{~d}$ & LTR 17 & $06,0 \mathrm{~d}$ & LTR5 & $9,3 \mathrm{~d}$ \\
\hline LTR232 & $10,0 \mathrm{c}$ & LTR 228 & $0,0 \mathrm{~d}$ & LTR 13 & $0,0 \mathrm{~d}$ & LTR 18 & $6,4 \mathrm{e}$ \\
\hline $\mathrm{CV}(\%)$ & 12,879 & & 19,402 & & 15,509 & & 6,322 \\
\hline
\end{tabular}

\footnotetext{
(1) Médias seguidas pela mesma letra na vertical não diferem entre si pelo teste de Scott-Knott (5\% de probabilidade); médias de seis repetições.
} 
patogênese, as espécies podem se diferenciar no requerimento de amido. Isso explica a baixa agressividade dos isolados LTR5 e LTR206 pela carência de produção das enzimas requeridas para a degradação dos tecidos hospedeiros. Embora LTR13, LTR17 e LTR18 tenham apresentado uma agressividade intermediária em relação aos outros isolados, ressaltam-se as baixas taxas de produção das enzimas que auxiliam na agressividade.

Considerando-se que a celulase é uma enzima importante na degradação da celulose, que por sua vez é um dos substratos em maior quantidade na casca da manga, os isolados que mais produziram estas enzimas LTM207 e LTR23 não foram agrupados entre os mais agressivos, embora o LTR23 tenha se destacado na produção das enzimas celulolítica, lipolítica e proteolítica, demonstrando que outras enzimas como, por exemplo, a amilolítica ou uma ação conjunta dessas enzimas, possam ter maior influência para a nutrição desse fungo em manga, considerando que as amilases promovem a degradação do amido, principal polissacarídeo de reserva nas células vegetais, o qual pode ser utilizado como fonte de energia durante o crescimento e/ou esporulação. Resultado semelhante foi observado para o isolado LTR21, o qual foi mais hábil na produção das enzimas amilolítica, lipolítica e proteolítica.

Os halos de degradação de amido, lipídio e proteína não se correlacionaram com a agressividade cujos coeficientes de correlação (r) e probabilidade foram -0,0297 ( $\mathrm{p}=0,4338)$-amilolítica; -0,2215 ( $\mathrm{p}=0,1041)$-lipolítica e $0,1314(\mathrm{p}=0,2295)$-proteolítica. Almeida \& Coelho (2) também não verificaram correlação dessas enzimas com os dados de agressividade no patossistema Colletotrichum sp. x maracujá amarelo, conflitando com os resultados obtidos por Couto et al. (6), que encontraram correlação positiva entre a atividade amilolítica e a agressividade no patossistema C. musae $\mathrm{x}$ banana e por Marchi et al. (14) que constataram correlação com a atividade dessa enzima com a agressividade de Alternaria solani em tomateiro. No presente estudo apenas a atividade celulolítica apresentou correlação com a agressividade 0,3681 ( $\mathrm{p}=0,0161$ ). Considerando que a celulose é um componente abundante da parede celular dos vegetais e que as celulases são enzimas envolvidas na degradação da celulose, esta interação corrobora para explicar a capacidade patogênica e agressiva dos isolados.

Lasiodiplodia theobromae produz uma ampla faixa de enzimas capazes de destruir os componentes estruturais dos tecidos das plantas hospedeiras (20), o que explica essa diferença na produção de enzimas por estes isolados. Diversos autores já demonstraram maior ou menor capacidade de fungos produzirem enzimas em substratos sólidos com a finalidade de diferenciar espécies ou caracterizarem isolados de uma mesma espécie $(6,9)$, entretanto com $L$. theobromae, isolados de mangueira, há necessidade de mais investigações.

Os resultados obtidos pela análise do perfil eletroforético de isoenzimas e proteínas estão esquematizados nas figuras 1 e 2 .

Os isolados de L. theobromae utilizados neste trabalho apresentaram comportamento polimórfico em relação às atividades enzimáticas. Os dados dos coeficientes de similaridade para proteínas totais (C1) mostram que a maior relação ocorreu entre os isolados LTR19 e LTF20; LTR19 e LTR24 (80\%), seguidos de LTR13 e LTR17 (75\%); LTR27 e LTF28 (66,66\%). Os demais isolados também apresentaram semelhança significativamente elevada (LTF1 e LTR9; LTF1 e LTR13; LTF1 e LTR17; LTR2 e LTR9; LTR2 e LTR10; LTR2 e LTR11; LTR20 e LTR23; LTR20 e LTR24; LTR20 e LTR31; LTR28 e LTR31) ou nenhuma relação, como LTF1 e LTR5; LTF1 e LTR19, LTR20 e LTR21. Entretanto, os isolados LTR19, LTR20, LTR21 e LTR24 apresentaram pouca semelhança com os outros isolados, destacando-se, entre estes, LTR21. A menor atividade foi exibida pelo
LTM7, que apresentou duas bandas fracas, enquanto que os isolados LTR12, LTR19, LTR20, LTR24 e LTF28 apresentaram cinco bandas. Verificou-se para LTR24 e LTF28 apenas uma banda em comum (CS=20), o mesmo foi observado entre LTR19 e LTF28. Os isolados LTR19 e LTR24 mostraram três bandas em comum (CS=60), confirmando uma alta semelhança fenotípica entre esses isolados.

Os isolados da coleta C2 comportaram-se de forma semelhante quando avaliados para proteínas totais. Entretanto, ressalta-se a alta semelhança entre os isolados LTR216 (coletado de ramo) e LTM220 (coletado da fruta) com $100 \%$ de similaridade, corroborando com a afirmativa de que não houve diferença entre isolados com relação ao órgão de coleta. Constatou-se, ainda, que os valores de CS foram mais elevados entre alguns isolados: LTR228 e LTR232 (CS=90,90); LTR212 e LTR220 (CS=66,66); LTR212 e LTR216 (CS=57,14) e que os isolados LTR225 e LTR232, foram os que apresentaram pouca semelhança genética com os outros da mesma coleta. Este estudo é pioneiro na utilização desta metodologia para diferenciar isolados de L. theobromae.

No sistema â-esterase, para os isolados da $\mathrm{C} 1$, todos mostraram expressiva variação quanto à mobilidade relativa e intensidade de coloração das bandas, exceto o LTR12 que apresentou uma única banda de intensidade forte com mobilidade relativa distinta $(\mathrm{RF}=$ 59,09). O número de bandas variou de uma a quatro. Os isolados LTR10 e LTR13 apresentaram número e mobilidade relativa de bandas idênticas $(\mathrm{RF}=42,72 ; 48,18 ; 54,54 ; 61,81)$, embora a intensidade das bandas tenha variado; isso foi verificado também entre LTR23 e LTR25 $(\mathrm{RF}=49,09 ; 54,54 ; 63,63 ; 70,90)$. Quanto aos isolados da $\mathrm{C} 2$, constataram-se resultados semelhantes em relação ao polimorfismo. Entretanto, isolados com perfil de duas bandas foi predominante (LTR203; LTR206; LTM220; LTM221; LTM222, LTR225 e LTR232), enquanto que LTM207 e LTR216 apresentaram maior número de bandas (cinco). A similaridade entre os isolados foi variável, excetuando-se LTR228, o qual não se agrupou apenas com o LTR31 e com alta similaridade $(\mathrm{CS}=66,66)$.

Pelo sistema â-esterase, foi possível distinguir variação e semelhança inter e intraespecífica entre os isolados de L. theobromae aqui estudados, corroborando com o estudo de Lima et al. (10) que analisaram isolados de $L$. theobromae coletados de mangueiras e verificaram comportamento diferenciado entre eles, os quais, exibiram três padrões distintos de bandas, evento antes justificado por Alfenas et al. (1), que relataram que essa variação na intensidade das bandas é normalmente provocada por diferença na atividade enzimática dos isolados e podem ser influenciadas por fatores ambientais ou de cultivo.

No sistema á-esterase, para isolados da C1, a maior similaridade foi observada entre LTR9 e LTR10 (CS=100) e LTR24 e LTR27 (CS=85,7). LTR12 expressou apenas uma banda fraca $(\mathrm{RF}=40,83)$, e não se correlacionou com nenhum outro isolado, demonstrando alta diferença fenotípica em relação aos demais. Semelhantemente, o LTR18 mesmo tendo exibido quatro bandas, não se correlacionou com qualquer outro; enquanto que LTR21 teve similaridade apenas com LTR25 (CS=28,56).

A análise dessa enzima para os isolados da $\mathrm{C} 2$ revelou que o único isolado que não apresentou relação com qualquer outro foi LTR203. LTM222 teve similaridade baixa apenas com LTR224 (CS=22,22), sendo o mesmo verificado para o isolado LTR228, o qual se correlacionou com LTR231 (CS=20). Moreno et al. (18) verificaram alto polimorfismo intraespecífico entre isolados de Pyrenophora triticirepentis, avaliados pelos sistemas de esterase, fosfatase e peroxidase, o que demonstra confiabilidade para o estudo taxonômico através dessas análises, com melhores resultados obtidos pelos dois primeiros 

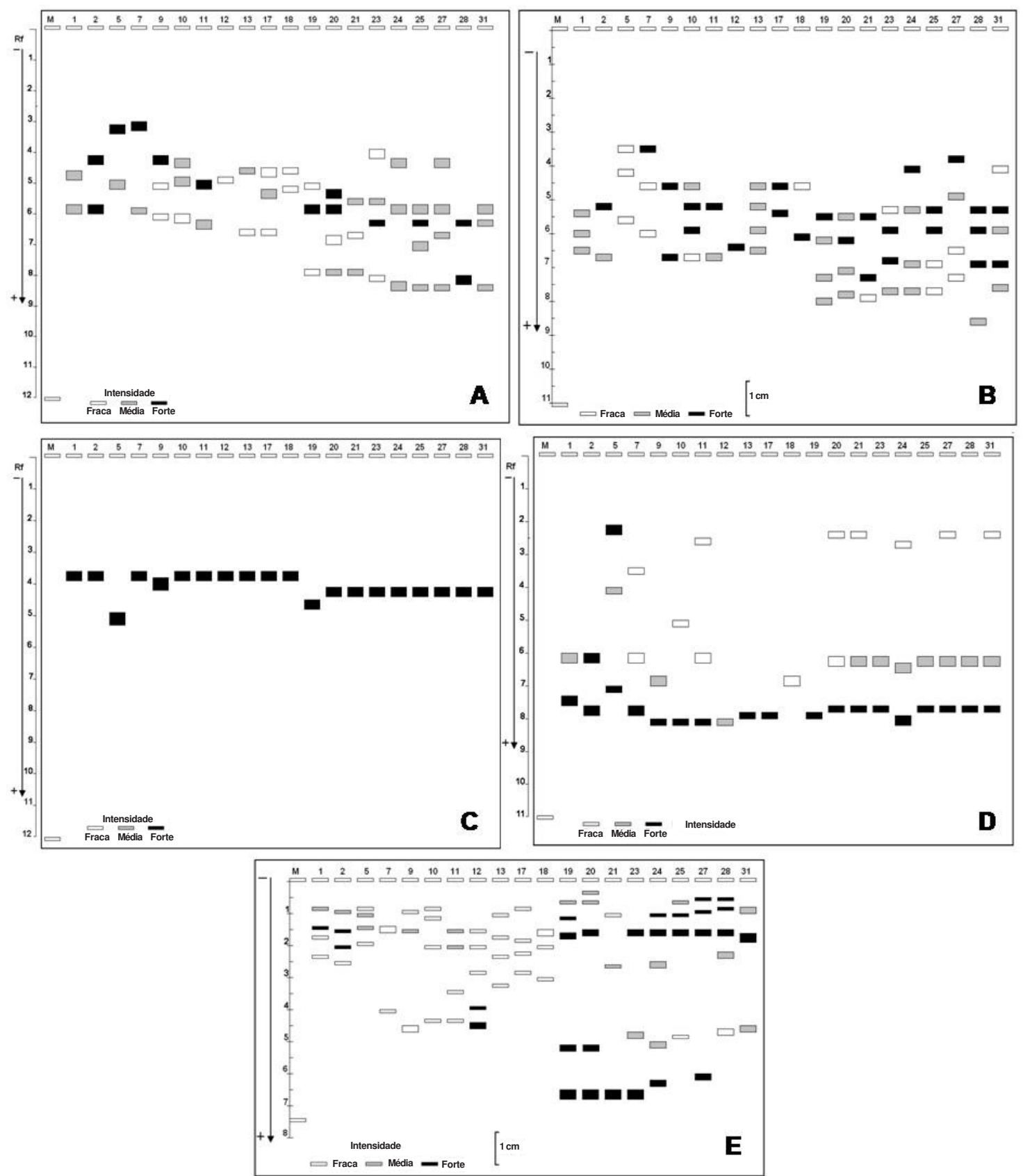

Figura 1. Zimogramas do perfil eletroforético de isoenzimas e proteínas produzidas pelos isolados de Lasiodiplodia theobromae (coleta 1). Números acima dos poços equivalem aos isolados: LTF1, LTR2, LTR5, LTM7, LTR9, LTR10, LTR11, LTR12, LTR13, LTR17, LTR18, LTR19, LTR20, LTR21, LTR23, LTR24, LTR25, LTR27, LTF28, LTR31, respectivamente. A= $\alpha$-esterase, $B=\beta$-esterase, $C=$ leucina aminopeptidase, $D=$ fosfatase ácida, E=proteinas totais

sistemas. Entretanto, Newton (19) relatou que fungos parasitas obrigatórios exibem pouca variação devido à uniformidade do substrato, diferente dos fitopatógenos facultativos que estão mais expostos a diferentes substratos, bem como a variações ambientais.

No sistema leucina-aminopeptidase, todos os isolados da C1 exibiram bandas monomórficas com exceção de LTR5, LTR9 e LTR19 que formaram dois grupos idênticos com a mesma intensidade de banda e mobilidade relativa: LTF1, LTR2, LTM7, LTR10, LTR11, LTR13, LTR17 E LTR18 (RF= 32,5); LTR20, LTR21, LTR23, LTR24, LTR25, LTR27, LTF28 e LTF31 (RF= 44), demonstrando $100 \%$ de similaridade. Dos três isolados que não tiveram correlação com qualquer outro isolado de L. theobromae, LTR5 exibiu bandas protéicas fracas e com baixa mobilidade relativa, fato também observado para o sistema fosfatase ácida, o qual apresentou agressividade à hospedeira. Essa observação revela que estas enzimas são relevantes para a nutrição de L. theobromae e reforça a hipótese de que o isolado com esta característica é uma raça fisiológica de $L$. theobromae. Os isolados da C2 também apresentaram bandas monomórficas. Contudo, verificouse maior dimorfismo entre estes. O LTR221, que esteve agrupado entre os mais agressivos, não exibiu perfil para essa enzima (leucinaaminopeptidase), o que também sugere tratar-se de uma nova raça, embora isso não o tenha diferenciado frente a outros isolados, na variação do número de bandas, nos demais sistemas enzimáticos. O LTM220 não exibiu similaridade com outro, da mesma coleta, neste 

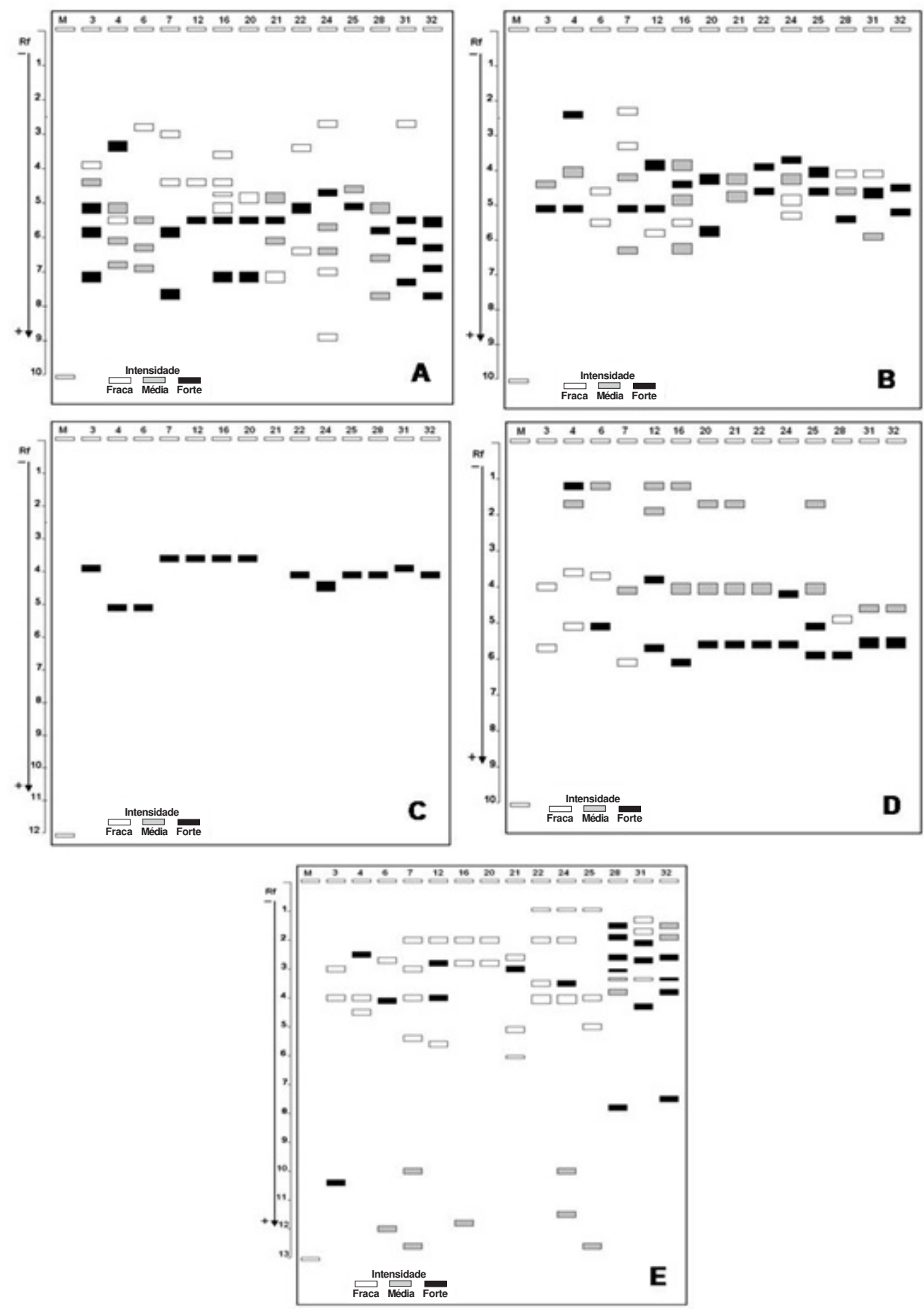

Figura 2. Zimogramas do perfil eletroforético de isoenzimas e proteínas produzidas pelos isolados de Lasiodiplodia theobromae (coleta 2). Números acima dos poços equivalem aos seguintes isolados: LTR203, LTR204, LTR206, LTM207, LTR212, LTR216, LTM220, LTM221, LTM222, LTR224, LTR225, LTR228, LTR231, LTR232, respectivamente. $\mathrm{A}=\alpha$-esterase, $\mathrm{B}=\beta$-esterase, $\mathrm{C}=$ leucina aminopeptidase, $\mathrm{D}=$ fosfatase ácida, $\mathrm{E}=$ proteinas totais.

sistema de análise.

Quanto ao sistema fosfatase ácida, o número de bandas variou de uma a três, para os isolados da C1, com predominância de três bandas. Lima Filho et al. (9) encontraram resultados semelhantes para isolados de Colletotrichum spp. de diferentes hospedeiros. Contudo, LTR12 e LTR13 foram diferentes dos outros isolados e exibiram apenas uma banda de forte intensidade da enzima. Isso também ocorreu com o isolado LTR19, o qual expressou uma banda, porém de fraca intensidade. Em contrapartida, esse último isolado expressou alto nível de agressividade, sugerindo que esta enzima não foi importante na patogenicidade. Embora a função desta enzima ainda não esteja esclarecida em interações planta patógeno, (18), existe relato de que esteja associada a mecanismos de defesa e maturação (25).

Para isolados da C2, o número de bandas variou de dois a quatro, excetuando-se os isolados LTR203, com duas bandas de fraca intensidade, LTM207, com uma banda fraca e outra média, LTR231 e LTR232, ambos com duas bandas, média e forte, e com mesma mobilidade relativa ( $R F s=49,47$ e 60,00, respectivamente) e LTM22 com uma banda média e uma forte. Estes resultados indicam uma grande variabilidade entre estes isolados, independente da época de coleta e do órgão do qual foram coletados.

Conclusivamente, os padrões eletroforéticos analisados pelos 
sistemas proteínas totais, $\alpha$-esterase, $\beta$-esterase, fosfatase ácida e leucina aminopeptidase apresentaram polimorfismo, demonstrando a diversidade na base genética dos isolados. Enquanto que nas bandas de mobilidades relativas, utilizadas para obtenção dos valores para expressar o CS, existem outros fatores a serem considerados, como concentração da enzima refletida pela coloração forte e largura da banda formada. Os valores dos Rfs revelaram o comportamento polimórfico das moléculas genéticas apresentando diferenças intraespecíficas presentes entre os isolados de L. theobromae estudados nesta pesquisa.

A atividade patogênica de alguns fungos, conforme Di Piero \& Pascholati (7) está diretamente relacionada com a sua capacidade enzimática. Em certos casos, correlações entre a presença de certas atividades enzimáticas e o desenvolvimento de sintomas de doenças têm sido encontradas $(6,9)$.

Considerando que isolados de $L$. theobromae originados de diferentes áreas geográficas e órgão das plantas hospedeiras apresentam variações em suas características morfológicas e fisiológicas, comportando-se de maneira distinta quanto ao crescimento, esporulação e patogenicidade $(15,21)$ e produção de enzimas extra e intracelulares, fazendo-se necessário mais conhecimento sobre seu comportamento. Contudo, este estudo oferece maiores subsídios na avaliação de uma população de isolados de L. theobromae, baseado em análise de isoenzimas, promovendo informações valiosas quanto à variabilidade genética de uma população desse fitopatógeno, em mangueira.

Os isolados de Lasiodiplodia theobromae foram patogênicos em manga, independente do órgão da planta do qual foram isolados e da época de coleta. Os isolados agruparam-se em três grupos de agressividade, sendo os mais agressivos isolados de ramos e de frutas. Não houve influencia da época de coleta, órgão da planta e região de origem dos isolados quanto à produção ou não de enzimas. Os isolados utilizados neste trabalho apresentaram comportamento polimórfico em relação às atividades enzimáticas. Os sistemas enzimáticos utilizados neste estudo foram eficientes para avaliarem o arsenal enzimático de L. theobromae, isolados de mangueira.

\section{REFERÊNCIAS BIBLIOGRÁFICAS}

1. Alfenas, A.C.; Peters, I.; Brune, W.; Passador, G.C. Eletroforese de proteínas e isoenzimas de fungos e essências florestais. Viçosa: Universidade Federal de Viçosa, 1991. 242p.

2. Almeida, L.C.C.; Coelho, R.S.B. Efeito de indutores químicos no controle da antracnose do maracujá amarelo pós-colheita. Fitopatologia Brasileira, Brasília, DF, v. 31, p.318-319, 2006.

3. Blum, L.E.B.; Cares, J.E.; Uesugi, C.H. Fitopatologia: o estudo das doenças de plantas. Brasília, DF, Ceres, 2006.

4. Burgess, T.I.; Barber, P.A.; Mohali, S.; Pegg, G.; Berr, W.; Wingfield, M. Three new Lasiodiplodia spp. from the tropics, recognized based on DNA sequence comparisons and morphology. Mycologia, New York, v.98, n.3, p. 423-435, 2006.

5. Cardoso, J.E.; Wilkinson, M.J. Development and characterization of microsatellite markers for the fungus Lasiodiplodia theobromae. Summa Phytopathologica, Botucatu, v. 34, n.1, p. 55-57, 2008.

6. Couto, E.F.; Menezes, M.; Coelho, R.S.B. Avaliação da patogenicidade e diferenciação enzimática em meio sólido específico de isolados de Colletotrichum musae. Summa Phytopathologica, Botucatu, v.28, n.3, p.260-266, 2002.

7. Di Piero, R.N.; Pascholati, S.F. Produção de celulases por Fusarium oxysporum f.sp. vasinfectum e seu papel na patogenicidade em algodoeiro. Summa Phytopathologica, Jaboticabal, v.26, n.3, p.336-341, 2000.

8. Hansen, E.M.; Brasier, C.M.; Shaw, D.S.; Hamm, P.B. The taxonomic structure of Phytophthora megasperma: evidence for emerging biolo- gical species groups. Transactions of the British Mycological Society, Cambridge, v.87, p.557-573, 1986.

9. Lima Filho, R.M.; Oliveira, S.M.A.; Menezes, M. Caracterização enzimática e patogenicidade cruzada de Colletotrichum spp. associados a doenças de pós-colheita. Fitopatologia Brasileira, Brasília, DF, v. 28, n.6, 2003.

10. Lima, J.A.S., Martins, L.S.S.; Tavares, S.C.C. Caracterização isoenzimática de quinze isolados de Botryodiplodia theobromae Pat. provenientes de diferentes hospedeiros. Fitopatologia Brasileira, Brasília, DF, v.22, p.322, 1997.

11. Lima, J.S.; Cardoso, J.E.; Moreira, R.C.; Alves, E.S.; Melo, J.G.M. Caracterização cultural de isolados de Lasiodiplodia theobromae e patogenicidade em plantas de aceroleira. Ciências Agrárias e Biológicas, Chapadinha, v. 6, n.1, p.10, 2012.

12. Lins, S.R.O.; Alves, E.; Oliveira, S.M.A. . Estudos da interação Lasiodiplodia theobromae x mangueira e caracterização morfológica de isolados do patógeno. Acta Microscopica, Caracas, v. 19, p. 221-231, 2010 .

13. Lins, S.R.O.; Oliveira, S.M.A.; Xavier, A.S.; Randau, K.P. Prospecção fitoquímica de extratos de plantas e controle da podridão peduncular em manga. Revista Brasileira de Ciências Agrárias, Recife, v.7, n.1, p.97-103, 2012.

14. Marchi, C.E.; Borges, M.F.; Mizubuti, E.S.G. Atividades amililítica e pectinolítica de Alternaria solani e a relação com a agressividade em tomateiro. Summa Phytopathologica, Botucatu, v.32, n.4, p.345352, 2006.

15. Marques, M.W.; Lima, Nelson Bernardi; Morais Junior, M.A.; Barbosa, M.A.G.; Souza, B.O; Michereff, S.J.; Phillips, A.J.L.; Câmara, M.P.S. Species of Lasiodiplodia associated with mango in Brazil. Fungal Diversity, v. 61, p. 181-193, 2013.

16. Menezes, M.; Assis, S.M.P. Guia prático para fungos fitopatogenicos. 2. ed. Recife: UFRPE, 2004. 53 p.

17. Mohali1, S.; Burgess, T.I.; Wingfield, M.j. Diversity and host association of the tropical tree endophyte Lasiodiplodia theobromae revealed using simple sequence repeat markers. Forest Pathology, Berlin, v. 35, n.6, p.385-396, 2005.

18. Moreno, M.V.; Tacaltti, M.S.; Castro, A.M.; Perello, A.E. Isoenzime polymorfisms within Pyrenophora tritici-repentis population in Argentina. World Journal of Microbiology and Biotecnology, New York, v.24, p.849-860, 2008.

19. Newton, A.C. Markers in pathogen populations. In: Day, P.R.; Jellis; G.J. (Eds.). Genetics and plant pathogenesis. Oxford: Blackwell Scientific Publications, 1987. p.187-194.

20. Nunes, F. M.; Oliveira, M.C.F.; Andrade Neto, M.; Rodrigues-Filho, E.; Viana, F. M. P.; Ferreira, V.M.; Mafezoli, J. Metabólitos secundários do fitopatógeno Lasiodiplodia theobromae. 2006. 29a Reunião Anual da Sociedade Brasileira de Química, Águas de Lindóia. Disponível em: < http://sec.sbq.org.br/cd29ra/programa.pdf>. Acesso em 19 de agosto de 2013.

21. Pereira, A.L.; Silva, G.S.; Ribeiro, V.Q. Caracterização fisiológica, cultural e patogênica de diferentes isolados de Lasiodiplodia theobromae. Fitopatologia Brasileira, Brasília, DF, v.31, p. 572-578, 2006.

22. Queiroz, G.O.; Jordão, R.C.C.; Salgueiro, A.A. Seleção de microrganismos produtores de celulases e de lacases a partir de efluente de fábrica de papel. Revista Química \& Tecnologia, Recife, v.1, n.1, p.7-10, 2002.

23. Shahbaz, M.; Iqbal, Z.; Saleem, A.; Akbar Anjum, M. Association of Lasiodiplodia theobromae with different decline disorders in mango (Mangifera indica L.). Pakistan Journal of Botany, Karachi, v.41, n.1, p.359-368, 2009.

24. Varma, V.; Bilgrami, K.S. New host records of Botriodiplodia theobromae. Indian Phytopathology, New Delhi, v.30, n.4, p.579, 1997.

25. Vidigal, D.S.; Dias, D.C.F.S.; Von-pinho, E.V.R.; Dias, L.A.S. A1terações fisiológicas e enzimáticas durante a maturação de sementes de pimenta (Capsicum annum L.). Revista Brasileira de Sementes, Lavras, v.31, n.2, p.129-136, 2009.

26. Zambolin, L.; Junqueira, N.T.V. Manejo integrado de doenças da mangueira, p. 377-408. In: Rozane, D.E.; Darezzo, R.J.; Aguiar, R.L.; Aguilera, G.H.A.; Zambolim, L. Manga: produção integrada, industrialização e comercialização. Viçosa : UFV, 2004. 571p. 